Statistica Neerlandica (2006) Vol. 60, nr. 2, pp. 85-111

\title{
'Rotterdam econometrics': an analysis of publications of the Econometric Institute 1956-2004
}

\author{
H. K. van Dijk*, J. F. Kaashoek† and A. P. M. Wagelmansł \\ Econometric Institute, Erasmus University Rotterdam, P.O. Box 1738, \\ 3000 DR Rotterdam, Netherlands
}

\begin{abstract}
The high ranking of the Econometric Institute, as listed in recent leading scientific journals, is examined for a 50 -year period using similar standard measures. The distribution of the publications over different research areas is analyzed and a time-series model is specified to describe and forecast the publication pattern.
\end{abstract}

Keywords and Phrases: ranking, history, time series.

\section{Introduction}

A valid measure for the evaluation of quality of research at a university institute is the content of published papers in international, leading scientific journals. The Econometric Institute at Erasmus University has, during it 50-years of existence, more than 1350 papers with more than 21,000 pages published in (mostly) international leading journals in econometrics, operations research and related fields. The topics range from econometric inference in economic modelling processes and decision methods in management science to optimization methods in transportation and risk analysis in finance, just to name a few general fields. As such, the staff of the Econometric Institute has contributed much to the high standing of the Erasmus School of Economics in international economic sciences.

Although it is difficult to adequately measure scientific standing, nowadays research quality of universities and institutes is evaluated in several published rankings. We name the following three:

1 According to the Times 4, February 2005, the Erasmus University belongs to the top five European universities in the Social Sciences and according to the German Wirtschaftswoche of March 2005, the School of Economics of the Erasmus University also belongs to the top five departments of economics.

\footnotetext{
*hkvandijk@few.eur.nl $\dagger$ tkaashoek@few.eur.nl twagelmans@few.eur.nl 
2 According to a study published in the Journal of the European Economic Association in 2003, Erasmus University ranks fifth in a European ranking based on an extensive set of high-quality journals; see LuBRANo et al. (2003, p. 1388).

3 According to a study published in Econometric Theory in 1998, the Erasmus University again ranked fifth in terms of scientific output.

Thus, according to a social science measure, an economic science measure and an econometric field measure, Erasmus University ranks high in Europe and these measures suggest that a substantial part is due to the high standing of quantitative economic research within the Econometric Institute.

Given the unique data set of almost all international scientific publications of the Econometric Institute since 1956, we investigate in this paper whether the high reputation listed in recent journals was already in existence in the beginning of the institute and how this reputation moved through a 50 -year period.

Our analysis may be divided in to three parts. We present some stylized facts on the number of publications per year over a period of 50-years and how this is distributed over different research areas and certain high-quality journals. Here, we also present a quality analysis according to the international and national rating methods. In simple words: would the researchers of the 1950s and 1960s also have a high international scientific reputation and would they, for instance, qualify as members of modern research schools like the Erasmus Research Institute for Management and the Tinbergen Institute? Secondly, using some basic econometric techniques from time series analysis (see HeIJ et al., 2004), we try to find some patterns in the output of the Econometric Institute. Time lags in publications, nonlinear trends, and interdependence between internal reports and scientific papers are analyzed. Finally, we investigate in an informal way whether some of the major papers written at the Econometric Institute are still being cited after many years. The duration effect is measured in a simple way.

The organization of the contents of this paper is as follows. In section 2 we present the stylized facts on the distribution of papers over time and over different research areas. In section 3 we use some basic econometric methods to model, estimate and forecast the number of publications. In section 4 we discuss the meaning of the citation patterns of some leading papers. Our conclusions are presented in section 5 . We emphasize that our analysis is done to the best of our knowledge but the contents of this paper also have an element of intellectual entertainment. Every reader is invited to make use of the data set and estimate her/his personal model.

\section{Stylized facts}

\subsection{The data}

The data are based on the Reports and Reprints series of the Econometric Institute. The Reports series contain working and discussion papers while the items of 


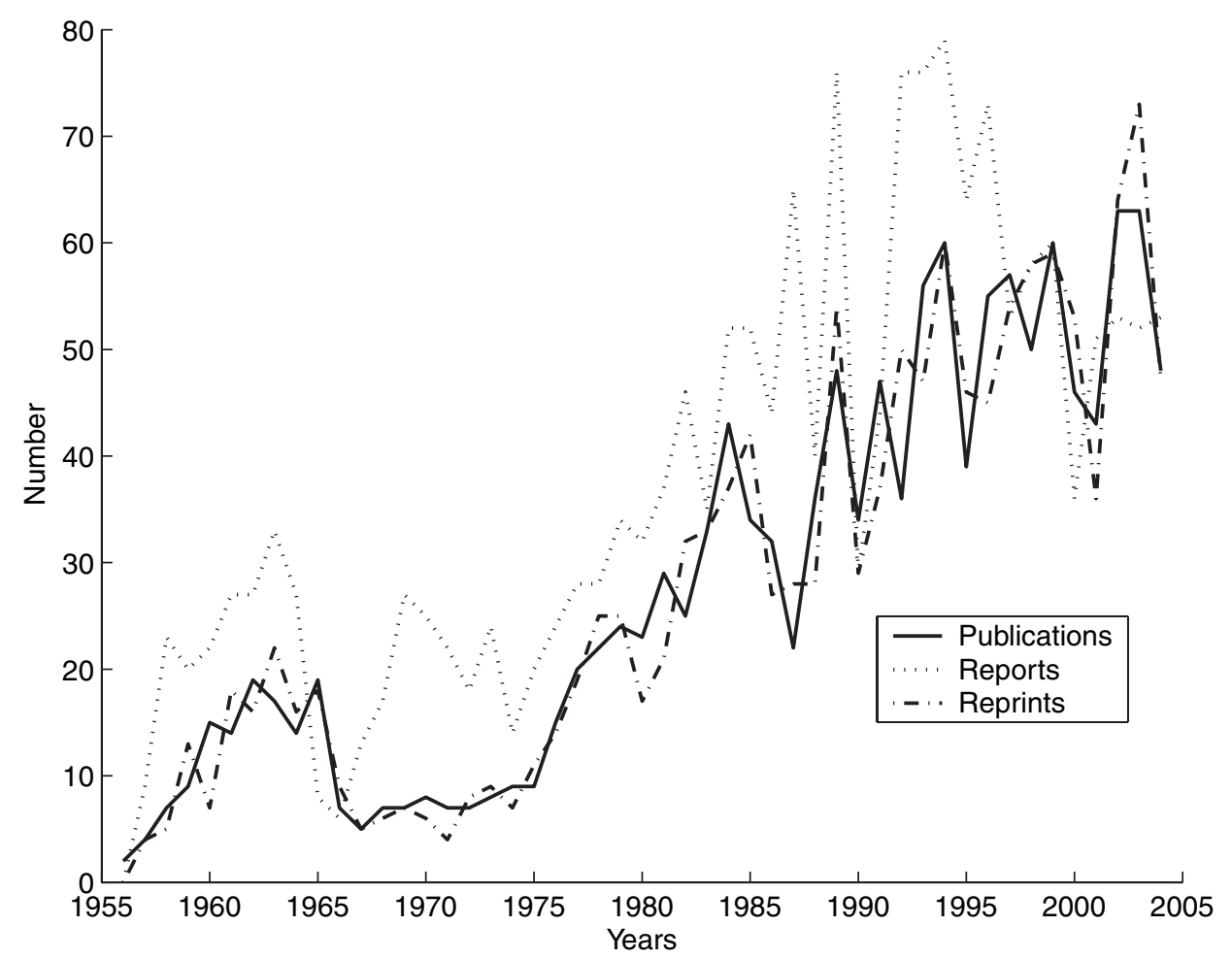

Fig. 1. Number of publications, reports and reprints 1956-2004.

the Reprints series are 1-1 copies of publications by members and guests of the institute (see Figure 1). Essentially, the only difference between a reprint and the underlying publication is the date of printing. For instance, a publication in a certain year may only become a reprint the next year. Our main data source is a database containing all publications present in the Reprint series with correct publication date, title, authors, number of pages and publication medium. Apart from the above-mentioned properties, the publications are also subdivided into journal and non-journal publications. In Table 1 some database facts are summarized.

The database has 1396 items. As not all data of 2005 are available, we restrict ourselves to the period 1956-2004. The series publications contains the total number of publications by year (see Figure 1).

Table 1. Summary of data.

\begin{tabular}{lcc}
\hline & \multicolumn{1}{l}{ Period } \\
\cline { 2 - 3 } & $1956-2004$ & $1956-2005^{\mathrm{a}}$ \\
\hline Total number of publications & 1357 & 1396 \\
Total number of publication pages & 21,397 & 22,075 \\
Total number of journal publications & 1119 & 1152 \\
Total number of journal publication pages & 17,205 & 17,775 \\
Total number of journals & 369 & 371 \\
\hline
\end{tabular}

Note: ${ }^{\mathrm{a}}$ Data collected till December 2005. 


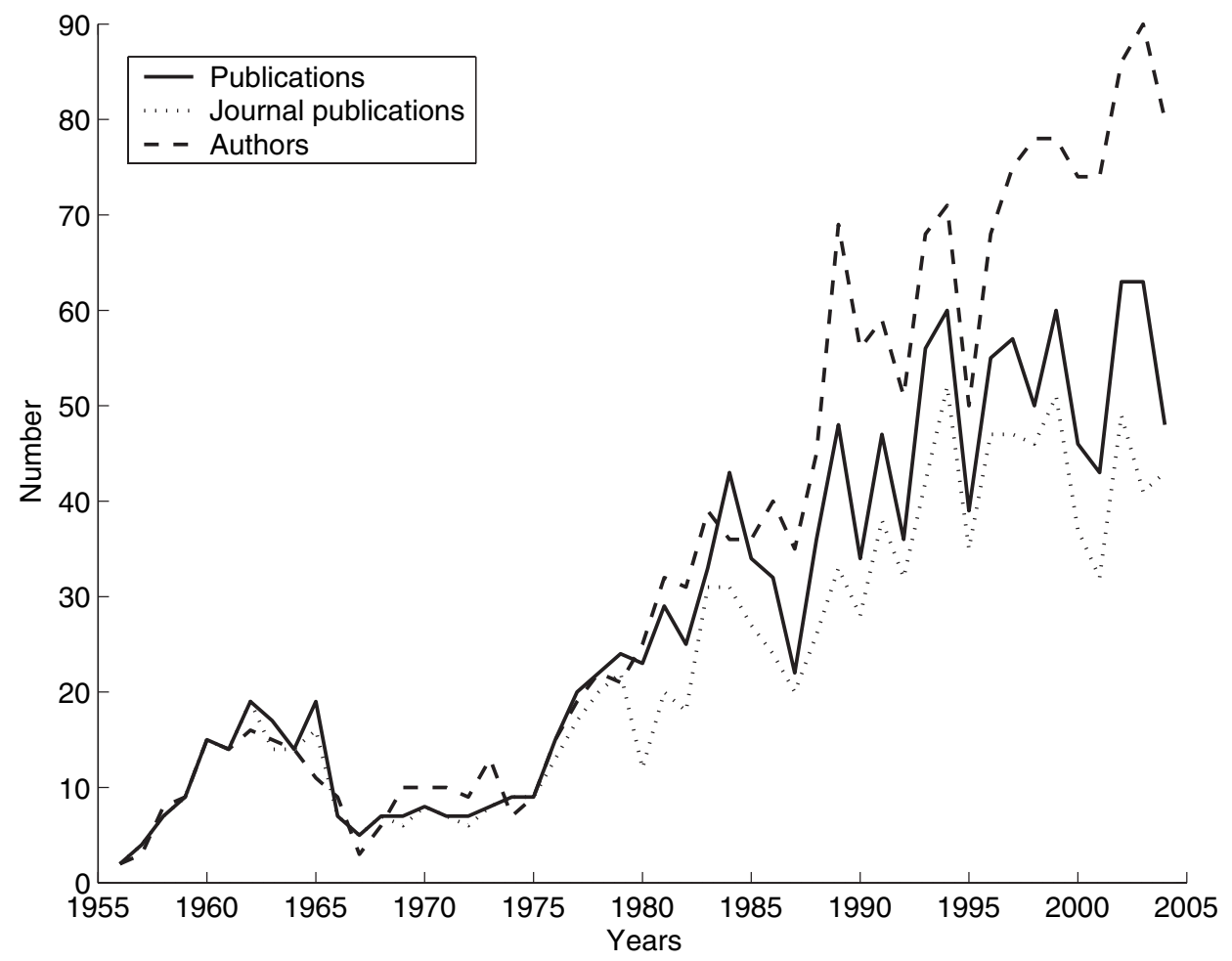

Fig. 2. Number of publications (all), journal publications and authors, 1956-2004.

Figure 2 shows, for each year, the total number of publications, the total number of journal publications and the number of different authors involved in all publications. All figures clearly show that after a relatively productive period, the scientific output of the institute started to decline (in volume) in the late 1960s. While all graphs show an upward trend after 1970, it is clear from Figure 2 that the number of authors is growing faster. Note that the group of authors include all persons involved and not the members of the Econometric Institute only. The increase in the number of authors per publication reflects that modern research has become more and more of a regular production process involving a team of workers.

\subsection{Changes in distributions of journal publications}

In Appendix A we give the 40 journals with the most published pages in the Reprints series. Although pages of different journals are not necessarily compatible, we believe that this list gives a good impression of the outlets in which members of the institute have typically published their work.

It is interesting to look for changes in the composition of the scientific output over time. This can be done from different perspectives. First, we have tried to classify the 369 journals according to their main subject areas into one of the following five 


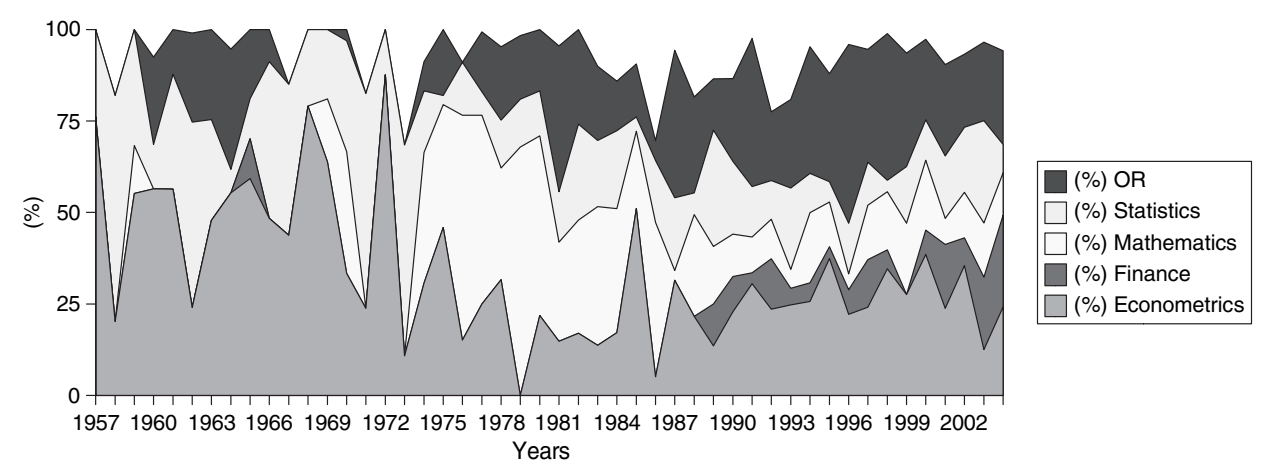

Fig. 3. Pages distribution over five typical groups of journals.

groups: econometrics, finance, mathematics, statistics or operations research (OR). About $80 \%$ of the journals have been classified in this way. The remaining journals have not been classified, because they mainly cover other research areas.

Figure 3 shows how the distribution of the number of published pages over the five mentioned subject areas has developed over time. It is interesting to note that publications in typical OR journals were almost absent in the period 1966-1973 and that the same period has the largest percentage of 'unclassified publications. Pure mathematics started to constitute a significant part of the output in the 1970s, when a full professorship in mathematics was established in the Econometric Institute, to which Michiel Hazewinkel was appointed. Mathematical finance has become a regular research topic at the institute only since the late 1980s, when Ton Vorst moved from pure mathematics to this area. The distribution over the five research areas appears to be fairly stable over the last 20-years.

Table 2 shows how publications in the different research areas are distributed over time (measured in publication pages; period 1956-2004). The columns below 'Distribution (cumulative)' show the number of years required to reach a certain percentage of the total number of publication pages. For instance, $50 \%$ of all publication pages on 'econometrics' were published in the first 17-years of the institute's existence. Here we note that econometrics and statistics exhibit the same pattern in that half the output was realized within the first 20-years. For OR and finance the more productive period is actually the last 20-years (which for finance is no surprise,

Table 2. Cumulative quartiles of publications, relative to 1956 .

\begin{tabular}{lrlll}
\hline & \multicolumn{3}{c}{ Distribution (cumulative) } \\
\cline { 2 - 5 } Research area & $25 \%$ & $50 \%$ & $75 \%$ & $100 \%$ \\
\hline Econometrics & 9 & 17 & 34 & 49 \\
Finance & 32 & 38 & 46 & 49 \\
Mathematics & 22 & 27 & 35 & 49 \\
Statistics & 7 & 16 & 32 & 49 \\
OR & 21 & 32 & 41 & 49 \\
\hline
\end{tabular}


Table 3. Quartile time intervals in years.

\begin{tabular}{lrrrrrr}
\hline & \multicolumn{3}{l}{ Distribution } & & & \\
\cline { 2 - 7 } Journal & First & $25 \%$ & $50 \%$ & $75 \%$ & $100 \%$ & Last \\
\hline Econometrica & 1957 & 4 & 3 & 5 & 32 & 2000 \\
European Journal of Operational Research (1977) & 1978 & 16 & 3 & 3 & 5 & 2004 \\
Journal of Econometrics (1973) & 1975 & 12 & 6 & 6 & 6 & 2004 \\
Journal of the American Statistical Associations & 1961 & 2 & 3 & 4 & 24 & 1994 \\
Management Science & 1960 & 2 & 3 & 16 & 21 & 2001 \\
Statistica Neerlandica & 1958 & 5 & 9 & 19 & 14 & 2004 \\
\hline
\end{tabular}

of course). Remarkable is the distribution pattern for mathematics: a quarter of all output was realized in approximately 5-years, namely 1978-1983.

To look at the changes in the distribution of journal publications from a different perspective, we now focus on a few individual journals. In Table 3, the distribution of publications in six journals are displayed. These journals are among the top 10 journals with the most published pages in the reprint series.

In case a journal was founded after 1956, the year of its first volume is indicated between brackets. The columns below 'Distribution' show the years in which the first and last publication has appeared, and the number of years between quartiles. For instance, of all publication pages in Econometrica, the first $25 \%$ was published in the period 1957-1961 $(=1957+4)$. Subsequently, it took 3-years to publish the next $25 \%$, and so on.

More detailed data of individual journals are presented in Figures 4-9 where the total number of pages by year are displayed. Clearly, journals such as Econometrica, JASA, Statistica Neerlandica and Management Science have published work of

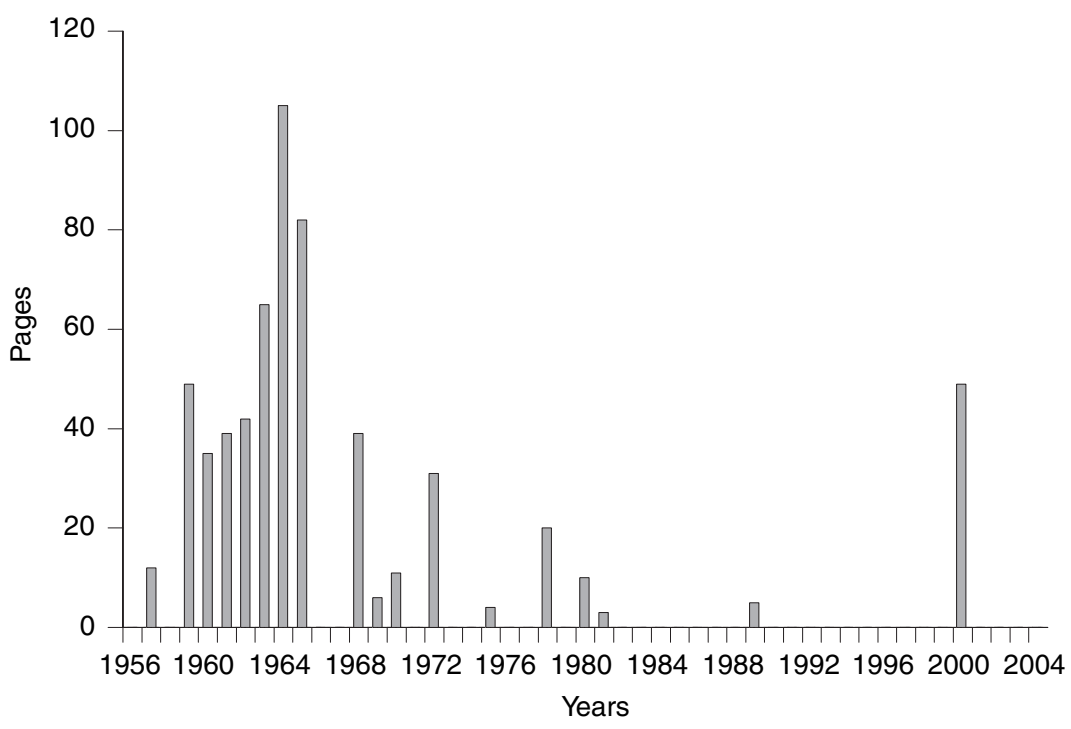

Fig. 4. Econometrica. 


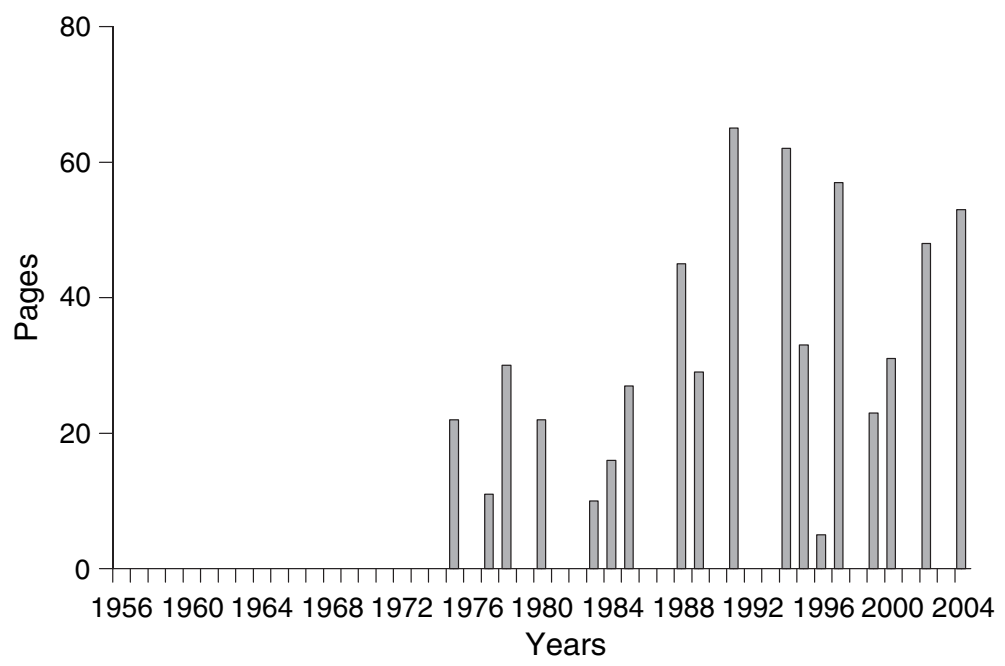

Fig. 5. Journal of Econometrics.

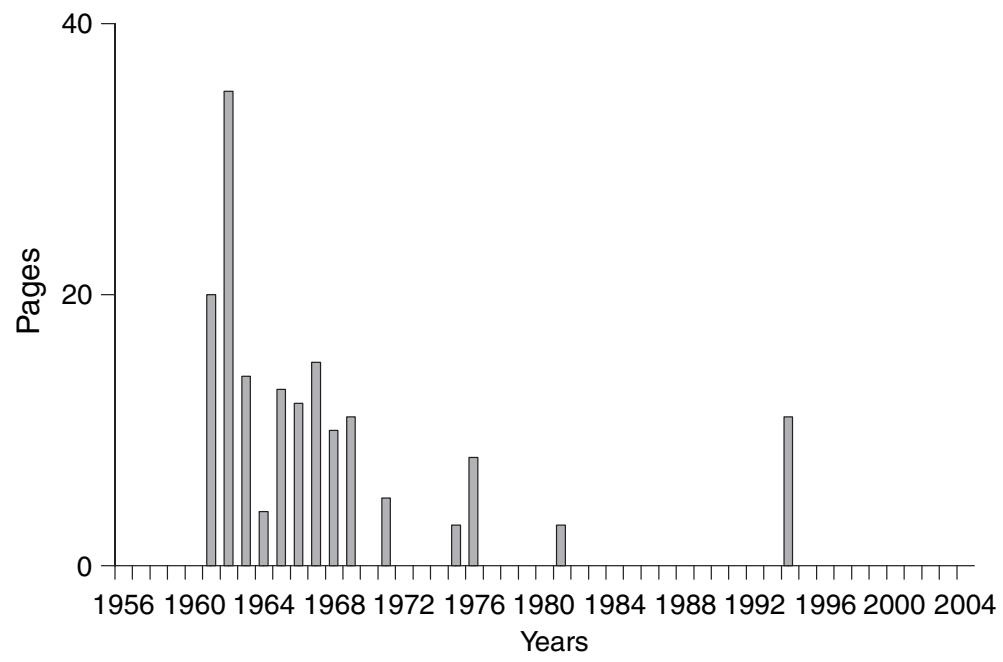

Fig. 6. Journal of the American Statistical Association.

Econometric Institute members much more frequently in the early years of the institute than in more recent years, despite the fact that these journals still exist. On the other hand, journals such as Journal of Econometrics and European Journal of Operational Research, that were founded in the 1970s, have become popular publication outlets.

This may reflect changes in the type of research conducted at the institute and a deliberate choice to focus on different publication outlets. It may also be possible, however, that the quality of the research has changed such that it has become much harder for members of the Econometric Institute to have their work published (c) VVS, 2006 


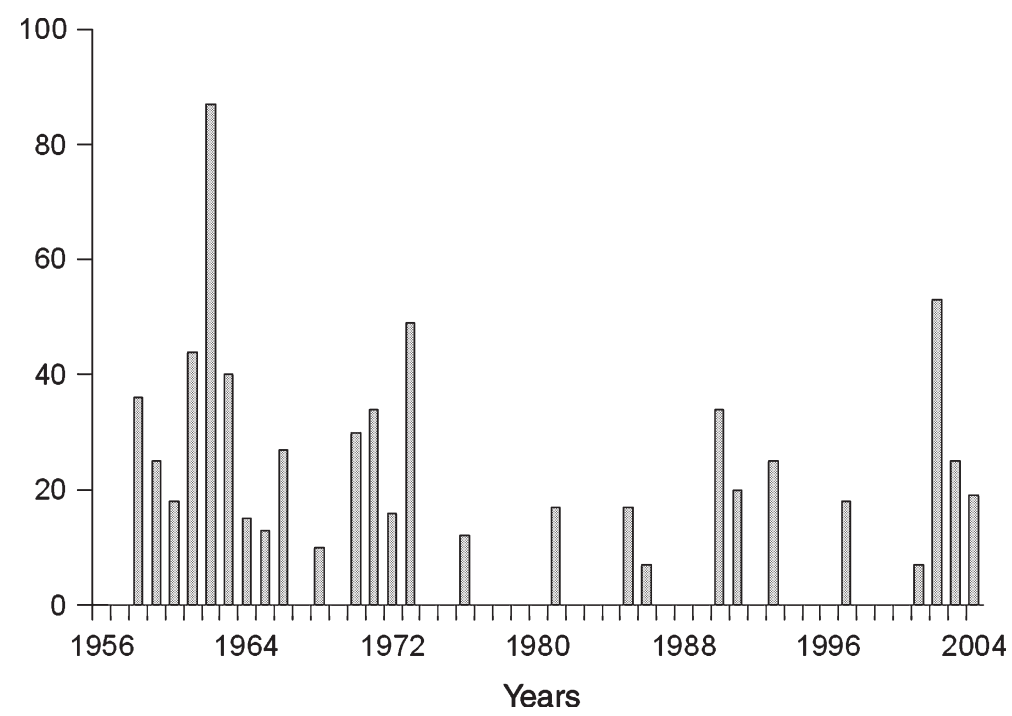

Fig. 7. Statistica Neerlandica.

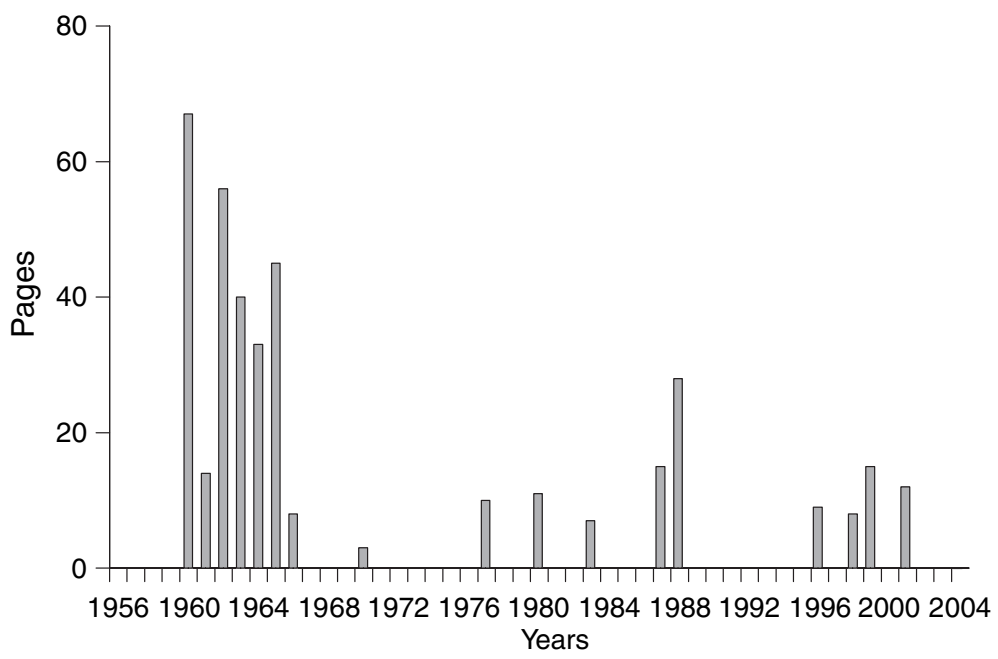

Fig. 8. Management Science.

in certain top journals. Therefore, we will focus on quality assessment in the next two subsections.

\subsection{Quality assessment based on rating methods from the literature}

In this subsection we evaluate the quality of the research output of the Econometric Institute by using rating methods taken from the literature. Among the many papers on rating and ranking economics journals and departments, we consider only (c) VVS, 2006 


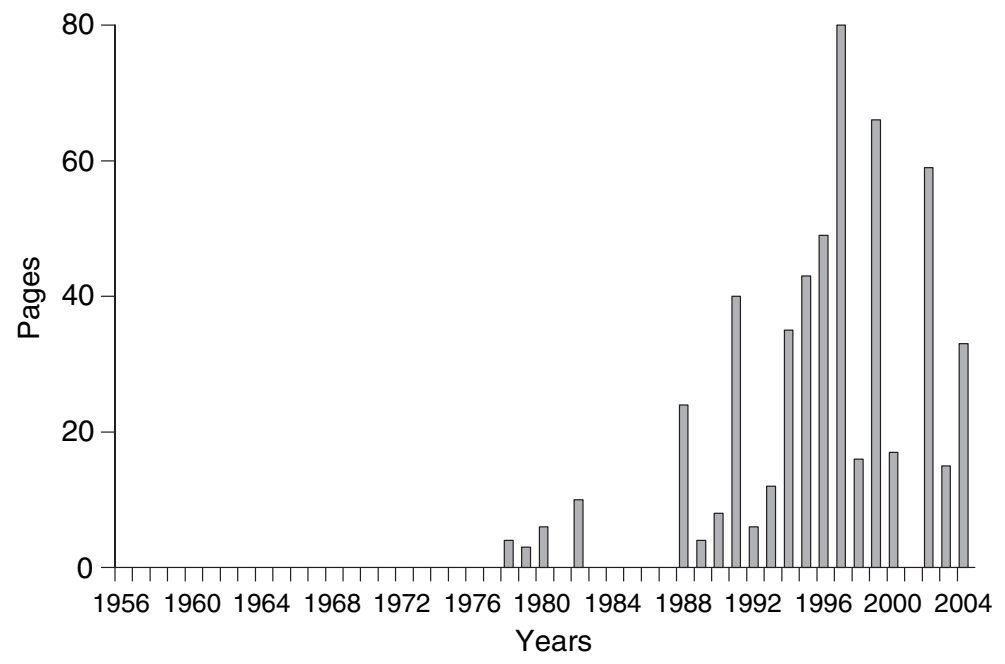

Fig. 9. European Journal of Operational Research.

Cribari-Neto, Jensen and Novo (1999), who base their ranking on publications in nine journals, and BaLtagi (2003) who use 15 journals (see Appendix B). These journals can be classified as mainly of 'econometrics nature'. The first group of journals will be called econometrics(1) and we will refer to the second as econometrics(2). Of the econometrics(1) list all nine journals have published work by members of the Econometric Institute, while of list econometrics(2) this holds for 14 of the 15 journals. Apart from the selected journals, the rating and subsequent ranking method of departments differ in the following aspects:

- Rating of journals: CRibari-Neto et al. (1999) and Baltagi (2003) use character counts of journal pages (standardized relative to Econometrica pages); see table B1 in Appendix B for the conversion factors.

- Ranking of departments: in CRIBARI-Neto et al. (1999) the score of an author is the number of standardized pages multiplied by $1 / \sqrt{n}$, where $n$ is the number of authors involved; in BaltaGi (2003) the factor is just $1 / n$. In both cases, the ranking of departments is based on summing up the scores of authors affiliated with the department ${ }^{1}$

- Year range: in Cribari-Neto et al. (1999) the range is 1986-1996; in Baltagi (2003) the range is 1989-1999.

While applying the above rating methods to the Econometric Institute (and comparing the outcomes) we have to make the following remarks:

- Both Cribari-Neto et al. (1999) and Baltagi (2003) do not rate the Econometric Institute, but the complete Erasmus School of Economics (of which the EI is only a subdepartment). 
- We have not been able to discriminate authors with respect to their affiliation (at time of publication); therefore, (standardized) pages contribute fully to the ranking of the institute.

As a consequence, the rating scores that we have calculated based on the methods taken from Cribari-Neto et al. (1999) and BALtagi (2003), will be different from that published in the referred papers. It is to be expected that counting standarized pages fully more than outweighs the fact that we restrict ourselves to publications of the Econometric Institute, i.e. our rating scores are always higher. This is no problem, however, because we are not so much interested in the scores themselves, but rather in how they have evolved over time. So instead of only one period of 11-years, we compute the scores for all 11-year periods ending in 1966 to 2004. In doing so, we assume that the conversion factors are constant over time.

Figures 10 and 11 display the time path of the rating score (11-year span) based on Cribari-Neto et al. (1999) and Baltagi (2003) respectively. Note that CribariNeto et al. (1999) assigned to the Erasmus School of Economics a score of 282.23 (1986-1996), while we obtained 391.18 over the same period.

Similarly, Baltagi (2003) calculated a score of 578.47 over the period 1989-1999, while our score for the Econometric Institute over that period is 780.06. These differences have already been explained. More importantly, however, the graphs exhibit a

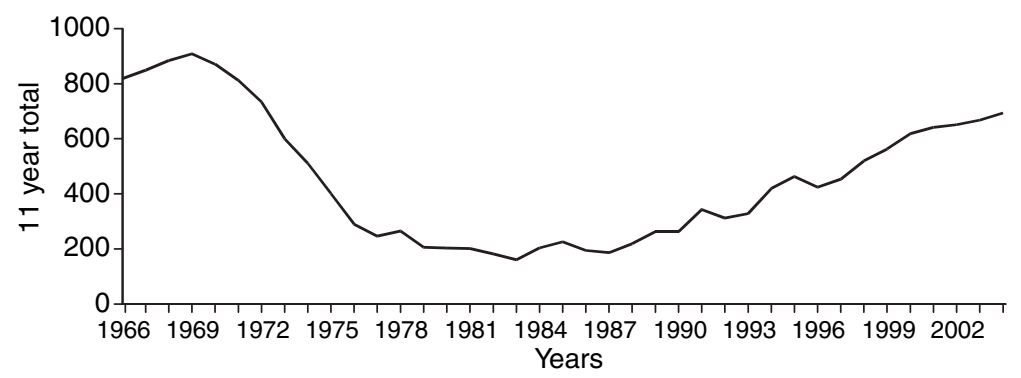

Fig. 10. Time path of scores based on list econometrics(1).

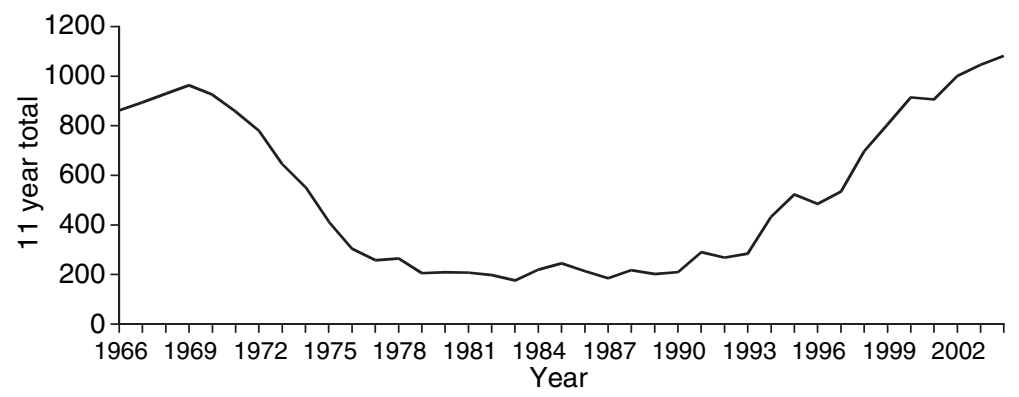

Fig. 11. Time path of scores based on list econometrics(2). 


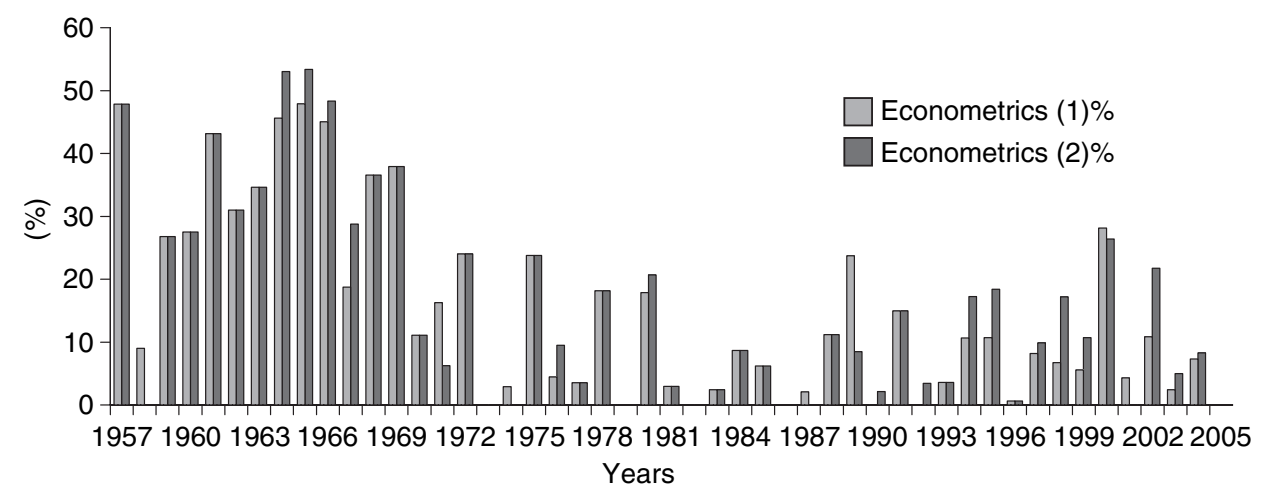

Fig. 12. Percentage publication pages in econometrics(1) or econometrics(2).

similar and remarkable pattern: both rating scores start to decline in the late 1960s, reaching their lowest value in mid-1980s (i.e. based on publications from the mid1970s to the mid-1980s), showing an upward trend ever since.

A further remark is to be made: while before 1970 the list econometrics(1) includes about $40 \%$ of all publications, after 1970 this never exceeds $25 \%$. For the list econometrics(2), those numbers are similar (see Figure 12). Clearly, this can be explained by the (re)new(ed) research activities in areas other than econometrics, in particular mathematics and OR.

\subsection{Quality assessment over time according to TI and ERIM}

The rating scores presented in the preceding subsection are based on publications in journals that focus mainly on econometrics, while the research carried out at the EI covers a wider range of topics. Therefore, we will now carry out a different quality assessment, which not only takes into account more research areas, but also reflects the research policy of the Erasmus School of Economics. The school participates on two so-called research schools, namely the Tinbergen Institute (TI) and the Erasmus Research Institute of Management (ERIM). TI is a collaboration with economics departments of the University of Amsterdam and the Free University Amsterdam, and its focus is on economic research (including econometrics). ERIM has been established jointly with the Erasmus School of Management and covers research areas typically found in business schools (including operations research, logistics, finance and marketing). The policy of the Erasmus School of Economics is that its faculty members should actively participate in at least one of the two research schools. This means that they have to meet the membership criteria of TI or ERIM. The main criterion of both research schools is that faculty members publish a certain number of articles in certain journals. TI and ERIM use different lists of journals that qualify and both differentiate within their own list. TI has AA-, A- and B-journals, which rate as 'excellent', 'very good' and 'good' respecively. In ๑vVs, 2006 


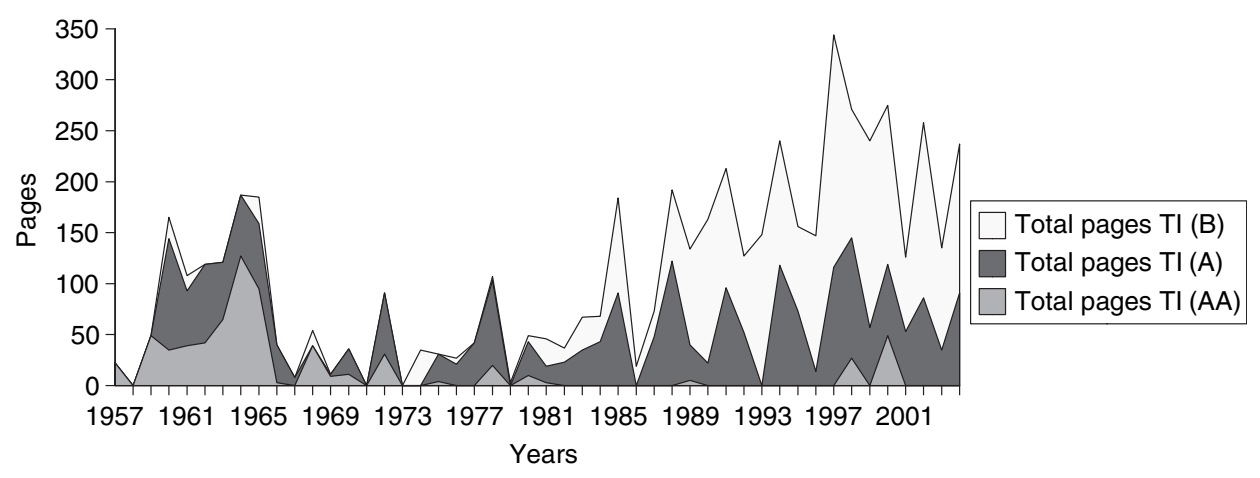

Fig. 13. TI publication pages.

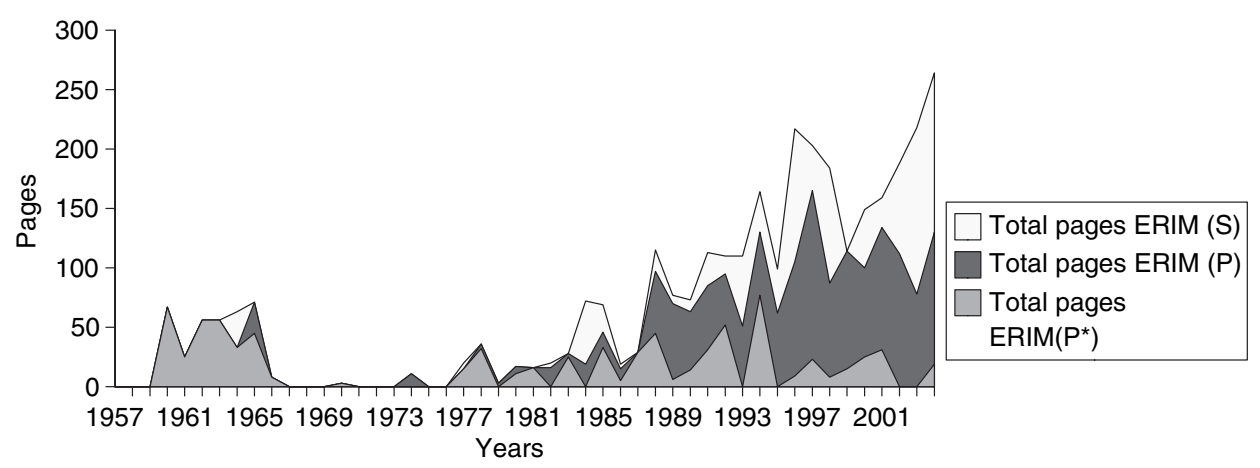

Fig. 14. ERIM publication pages.

ERIM, a similar rating is used for $\mathrm{P}^{*}-, \mathrm{P}-$ and S-journals. To give an indication of the type of journals on the TI and ERIM lists, the AA- and P*-journals are listed in Appendix C. The full journal lists can be found on the websites of the research schools [see TI ranking (2005) and ERIM ranking (2005)].

Figures 13 and 14 show for each year the number of pages published in the different journal categories of TI and ERIM respectively. Again, we notice in figure 13 the significant drop in volume in the mid-1960s. Although, in the last 20-years, the number of published pages in TI-journals is at least comparable with the level of the early 1960s, the distribution shows a tendency to the TI(B) category. The drop in publications is even more dramatic when looking at the ERIM journals in Figure 14. Publications were almost absent in the period 1966-1973. Later years show a strong recovery and a distribution that has become rather stable.

These figures illustrate the fact that the current research at the Econometric Institute is much more diverse than in the first years after it's founding. This refers both to the diversity of the research areas and to the fact that besides fundamental research solid applied research is also highly valued nowadays. 


\section{Interdependence, dynamics and forecasts}

A time series of 49 annual observations is available on the number of publications as well as on the number of annual reports of the staff of the Econometric Institute. By their very nature, the reports and publications series will have interdependence. In Figure 1 one may observe some typical time-series patterns:

- As expected, the reports series has a similar pattern as the publications series.

- There exists an autoregressive pattern in both series.

- The time-series pattern for both series appears to be nonlinear.

In this section, we analyze these typical phenomena using time-series models and methods; for details, see the 'Rotterdam' econometric textbook of HeIs et al. (2004, chapter 7).

Since the 1950s, the first feature, interdependence of two variables has been a major topic of econometric research. It is also known as simultaneity between two variables or as endogeneity of an explanatory variable in a regression model. A well-known example where simultaneity or endogeneity occurs is the standard market model of price determination, that is, prices and quantities are jointly determined. Other well-known examples of variables that show interdependence are sales and expenditures on marketing and personal income and years of education. The famous Cowles Foundation monographs 10 and 14 contain many innovative papers in this respect; see (Koopmans, 1950; Hood and Koopmans, 1953). Henri Theil's twostage least squares method became very popular in many fields of econometrics (see THEIL, 1953a,b) ${ }^{2}$.

We start our historically inspired analysis of interdependence in the context of a static linear regression model. In Table 4 the results of a static least squares regression are reported together with the results obtained through an instrumental variable regression method (which is equivalent to two-stage least squares; see equations 1 and 2). It is seen that the estimate of the coefficient $c_{0}$ has changed from 0.78 to 1.01 in a significant way.

$$
\begin{aligned}
& \text { publications }_{t}=d+c_{0} \text { reports }_{t}+\varepsilon_{t} \\
& \text { publications }_{t}=d+c_{0} \text { reports }_{t}+\varepsilon_{t} \\
& \text { Instrumental variable: } \text { publications }_{t-1}
\end{aligned}
$$

The question is whether we should have confidence in the result that reports of a current year have an effect of one on the publications in the same year, ignoring

\begin{tabular}{|c|c|c|c|c|c|c|c|}
\hline \multicolumn{4}{|c|}{ Equation 1} & \multicolumn{4}{|c|}{ Equation 2} \\
\hline Param. & Value & SE & Prob. & Param. & Value & SE & prob. \\
\hline$d$ & -1.53 & 3.3 & 0.64 & $d$ & -12.86 & 4. & 01 \\
\hline & 0.78 & 0.08 & & $c_{0}$ & 1.08 & 0.11 & 0.00 \\
\hline \multicolumn{8}{|c|}{ Descriptive statistics } \\
\hline & & $R^{2}$ & 0.0 & \multirow{2}{*}{\multicolumn{3}{|c|}{ Durbin-Watson stat. }} & 0.59 \\
\hline \multicolumn{3}{|c|}{ Durbin-Watson stat. } & 1.43 & & & & 1.71 \\
\hline
\end{tabular}
all dynamics ${ }^{3}$.

Table 4. Estimation results for equations (1) and (2). 
Since the 1970s the aspect of dynamics has become a major topic of research because of the autoregressive nature of many economic timeseries. Performing a least squares regression on reports and reports lagged several periods, it appears that reports lagged up to 5-years have a reasonably strong effect on current publications. This order of time lags has been determined through an extensive search procedure and it leads us to conclude that it takes approximately 1-5-years before a report is published in an international scientific journal. However, given the second data feature of both series, we repeat the exercise of a least squares regression comparison with an instrumental variable regression within an autoregressive distributed lag model with five time lags for each variable $[\operatorname{ARDL}(5,5)$; see equation (4)].

$$
\begin{aligned}
& \text { publications }_{t}=d+c_{0} \text { reports }_{t}+\sum_{k=1}^{5} c_{k} \text { reports }_{t-k}+\sum_{k=1}^{5} e_{k} \text { publications }_{t-k}+\varepsilon_{t} \\
& \text { publications }_{t}=d+c_{0} \text { reports }_{t}+\sum_{k=1}^{5} c_{k} \text { reports }_{t-k}+\sum_{k=1}^{5} e_{k} \text { publications }_{t-k}+\varepsilon_{t} \\
& \text { IV : reports } \\
& t-1
\end{aligned}
$$

The estimate of the $c_{0}$ coefficient of the endogenous variable now changes from 0.18 in equation 3 towards 0.42 in the IV regression of equation (4). Complete estimation results of equation (4) are reported in Table 5.

This change in coefficients is however not significant in a so-called Hausman test for endogeneity at the 5\% level but significant at a higher level. The overall fit and dynamic features of the ARDL $(5,5)$ with endogenous regressor, shown in Figure 15, gives us reasonable confidence that that both interdependence and dynamics are relevant within the ARDL $(5,5)$ specification. However, the ultimate test of this model is its forecasting ability ${ }^{4}$.

Table 5. ARDL (5,5) with IV regression results; see equation (4).

\begin{tabular}{lrll}
\hline Param. & Value & SE & Prob. \\
\hline$d$ & -4.21 & 3.17 & 0.19 \\
$c_{0}$ & 0.42 & 0.19 & 0.03 \\
$c_{1}$ & 0.07 & 0.12 & 0.52 \\
$c_{2}$ & -0.11 & 0.12 & 0.36 \\
$c_{3}$ & -0.22 & 0.11 & 0.05 \\
$c_{4}$ & 0.41 & 0.12 & 0.00 \\
$c_{5}$ & -0.15 & 0.13 & 0.25 \\
$e_{1}$ & 0.52 & 0.18 & 0.01 \\
$e_{2}$ & -0.22 & 0.18 & 0.23 \\
$e_{3}$ & 0.26 & 0.20 & 0.20 \\
$e_{4}$ & -0.37 & 0.18 & 0.05 \\
$e_{5}$ & 0.44 & 0.17 & 0.01 \\
Statistics & & & \\
$R^{2}$ & & & 0.91 \\
Durbin-Watson stat. & & & 2.01 \\
\hline
\end{tabular}




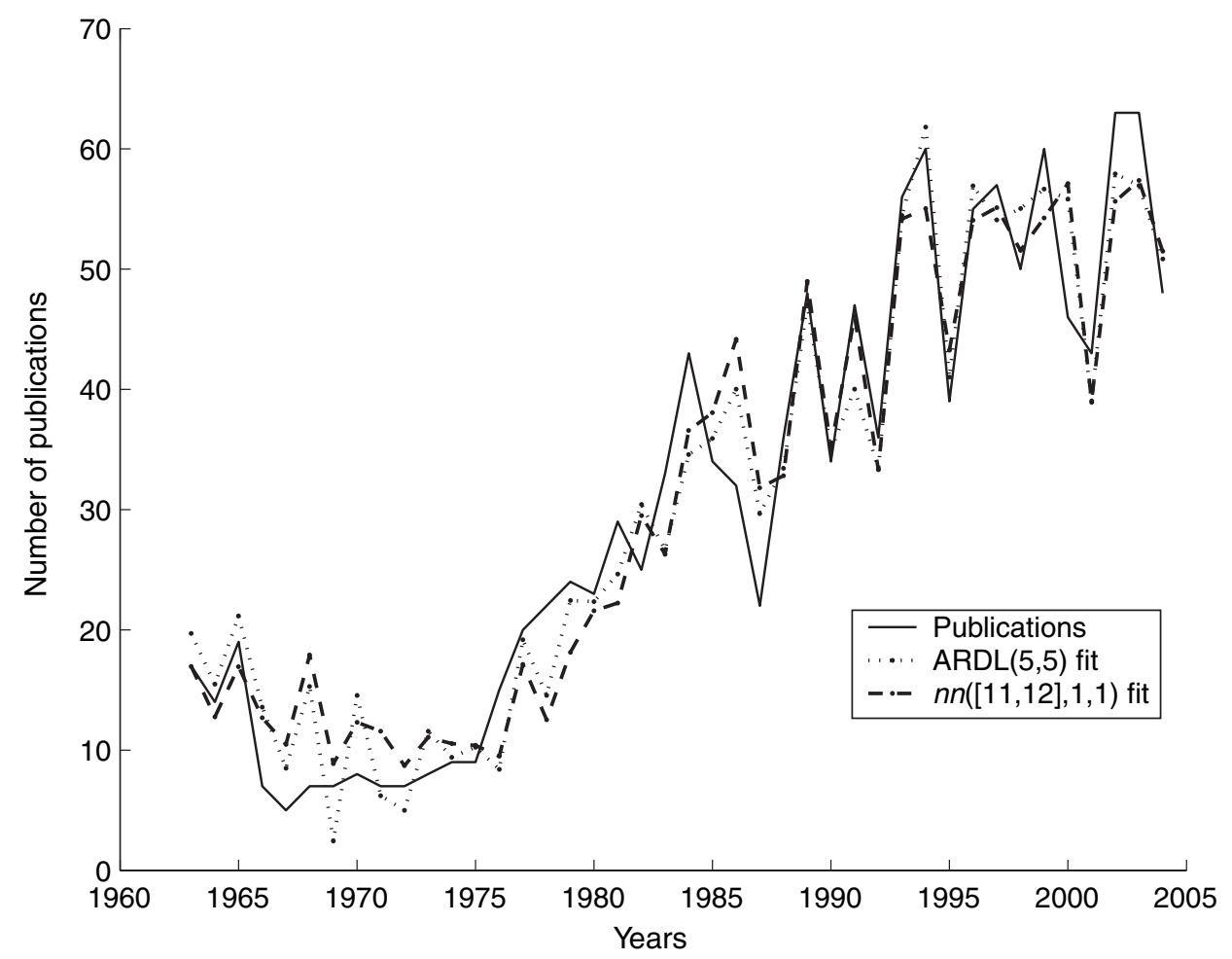

Fig. 15. Number of publications, $\operatorname{ARDL}(5,5)$ with IV and neural network fit.

As all lagged endogenous variables are included in the set of IV-variables, the ARDL(5,5) with IV model, [see equation (4)], can be written as:

$$
\text { publications }_{t}=d_{0}+c_{0} \widehat{\text { reports }}_{t}+\sum_{k=1}^{5} c_{k} \text { reports }_{t-k}+\sum_{k=1}^{5} e_{k} \text { publications }_{t-k}+\varepsilon_{1 t}
$$

where reports ${ }_{t}$ are the fitted values of the following equation:

$$
\text { reports }_{t}=d_{1}+\sum_{k=1}^{6} f_{k} \text { reports }_{t-k}+\sum_{k=1}^{6} g_{k} \text { publications }_{t-k}+\varepsilon_{2 t}
$$

To include our third feature, a nonlinear trend in the number of publications and the number of reports, we specify a nonlinear $\operatorname{ARDL}(5,5)$ model (see equation 6).

publications $_{t}=d_{10}$

$$
+d_{11} G\left(c_{0} \widehat{\text { reports }}_{t}+\sum_{k=1}^{5} c_{k} \text { reports }_{t-k}+\sum_{k=1}^{5} e_{k} \text { publications }_{t-k}\right)+\varepsilon_{1 t}
$$


where reports ${ }_{t}$ are the fitted values of the following equation:

$$
\text { reports }_{t}=d_{20}+d_{21} G\left(\sum_{k=1}^{6} f_{k} \text { reports }_{t-k}+\sum_{k=1}^{6} g_{k} \text { publications }_{t-k}\right)+\varepsilon_{2 t}
$$

with $G$ a nonlinear function

$$
G(x)=\frac{1}{1+\exp (-x)}, \quad x \in \mathbb{R}
$$

The model (6) consists of two neural networks with either 11 or 12 variable inputs and only one hidden layer cell and one output cell for each network. However, the outcome of network (6b) is used as an input of network (6a). We shall denote this configuration as $n n([11,12], 1,1)$. For details on neural network models we refer to Bishop (1995). The neural networks of model (6) can be interpreted as an extension of an autoregressive model with time-varying coefficients (see, e.g. KAASHOEK and van DiJK, (2003); van DiJK, 2004).

The neural network fit gives a $R^{2}$ equal to 0.92 for the number of publications series, only slightly better than the linear model ARDL $(5,5)$ with IV (see also Figure 15).

\subsection{Forecasts using ARDL and a flexible neural network}

A valid test of a model specification, is its short- and long-term predictive power. We compare forecasts of the ARDL(5,5)+IV model (equation 4) with the neural network specification of equation (6).

Both difference equations allow for generating 'orbits'; an orbit is a (solution) path with given initial value(s), mostly taken from actual values at a specific time index $t$; such a solution is also called a 'dynamical prediction'.

The reported forecasts of number of publications for 2005 and 2010 are 1-year ahead and 6-year-ahead predictions (with initial values from 2004 and below; see Table 6). However, for the long-run forecasts, we use two different initial values: one based on the data of 1963 (and before), and one on 2003. If present, a long-run forecast will be equal to (a) stable fix point(s) of the difference equations. In the case of the linear ARDL $(5,5)$ with IV specification, the model predicts, for both initial values a long-run forecast of 38.88 conform the only stable fix point of the model.

In contrast, the nonlinear specification of 6 has two different long-run forecasts: with initial values equal to 1963 data, the orbit tends to 14.09 publications while for

Table 6. Forecasting results for series 'publications'.

\begin{tabular}{llll}
\hline Model & \multicolumn{3}{l}{ Forecasts } \\
\cline { 2 - 4 } & 2005 & 2010 & Long run \\
\hline ARDL(5,5) with IV, equation (4) & 55.04 & 45.87 & 38.88 \\
$n n([11,12], 1,1)$, equation (6) & 51.36 & 55.52 & 14.09 or 55.61 \\
\hline
\end{tabular}




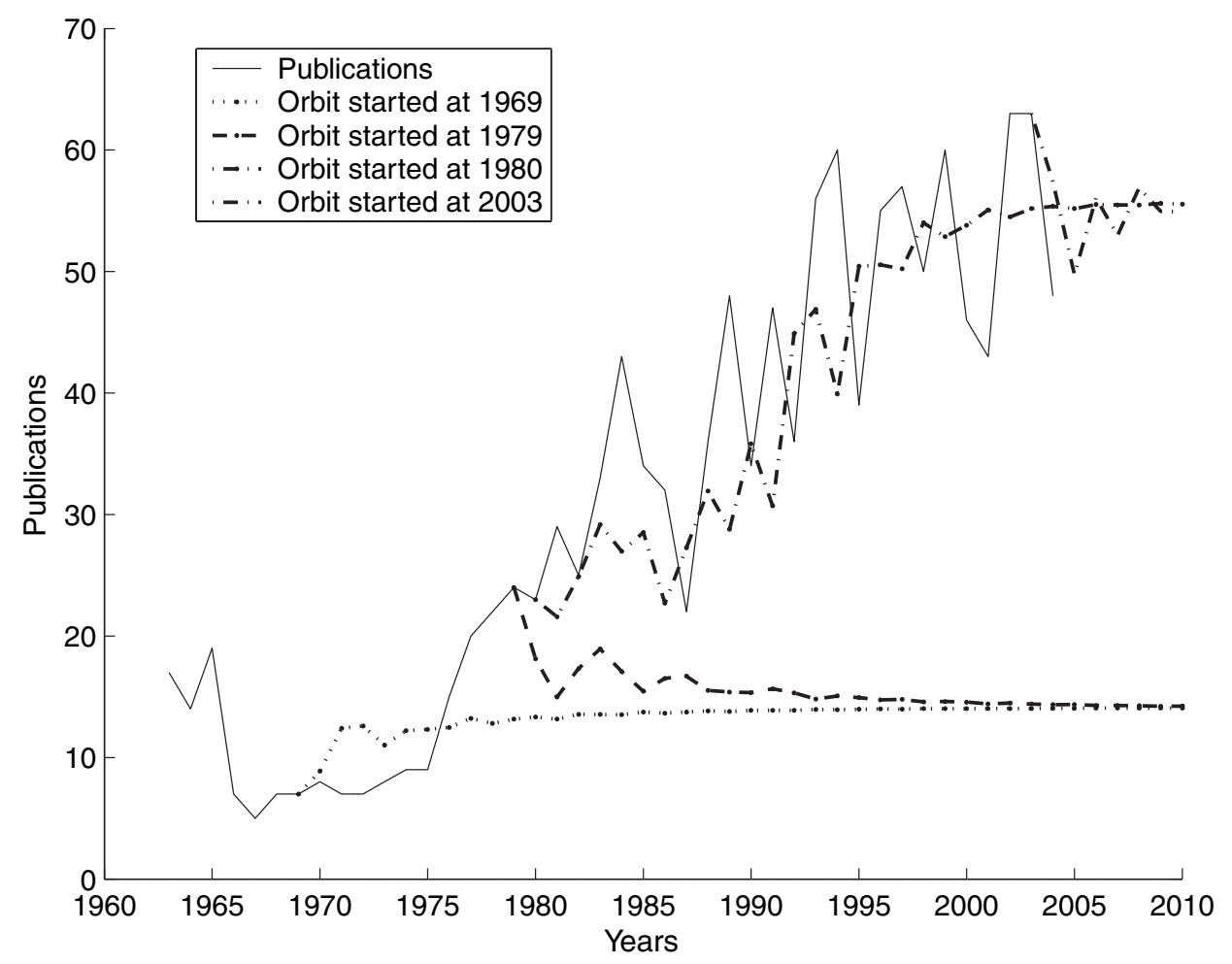

Fig. 16. Number of publications: forecasts by $n n([11,12], 1,1)$ (dotted lines).

2003, the long-run forecast is 55.61 (see Figure 16). In general, the difference equation (6) has at least two regimes (two different basins of attraction) with different asymptotic properties. With initial values from 1980 and later, the model predicts high outcomes (55.61), while with initial values equal to data before 1980, the predicted outcome will tend to 14.09. The nonlinear specification 6 reveals a structural change in about 1979/1980.

\section{Citations: duration patterns}

We present citation patterns of several published papers of the Econometric Institute based on the citation index of the Web of Science (2005). Our choice of papers includes the famous article of Arnold Zellner, 'An efficient method of estimating seemingly unrelated regressions and tests for aggregation bias', published in the Journal of the American Statistical Association in 1962. This paper has 1424 citations $^{5}$. Since only citation data by year are reported by Web of Science (2005) from 1988, the time-span is only from 1988-2005 (2006). Thus, in the case of the Zellner article, 779 citations belong to this period (see Figure 17). 


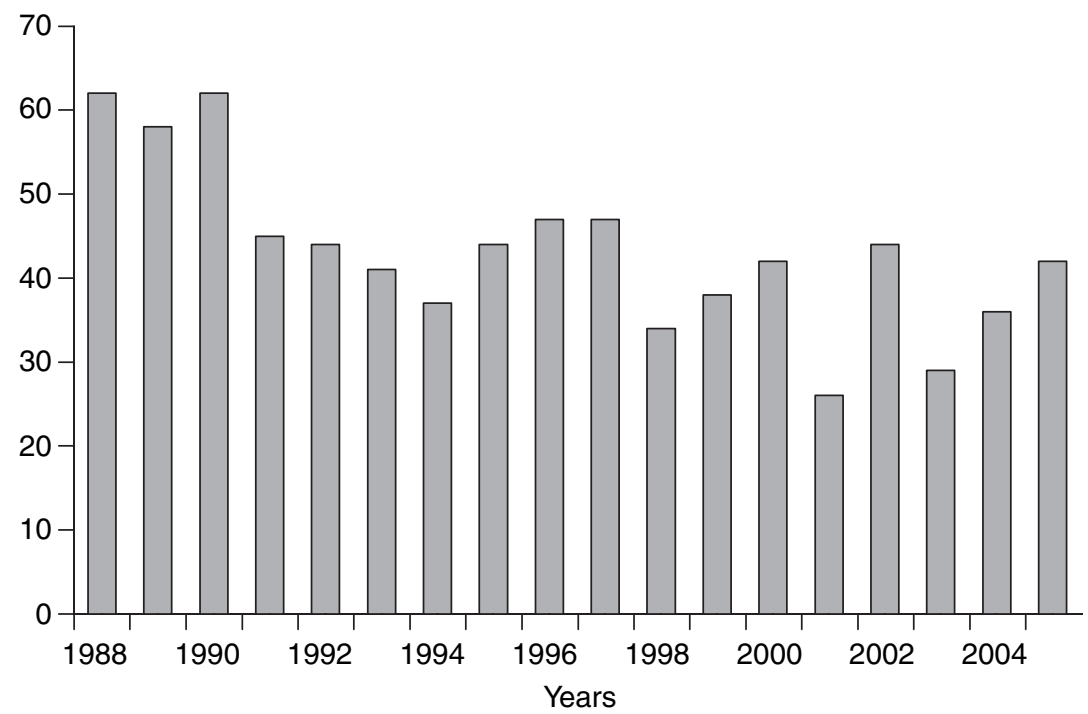

Fig. 17. ZeLLner (1962).

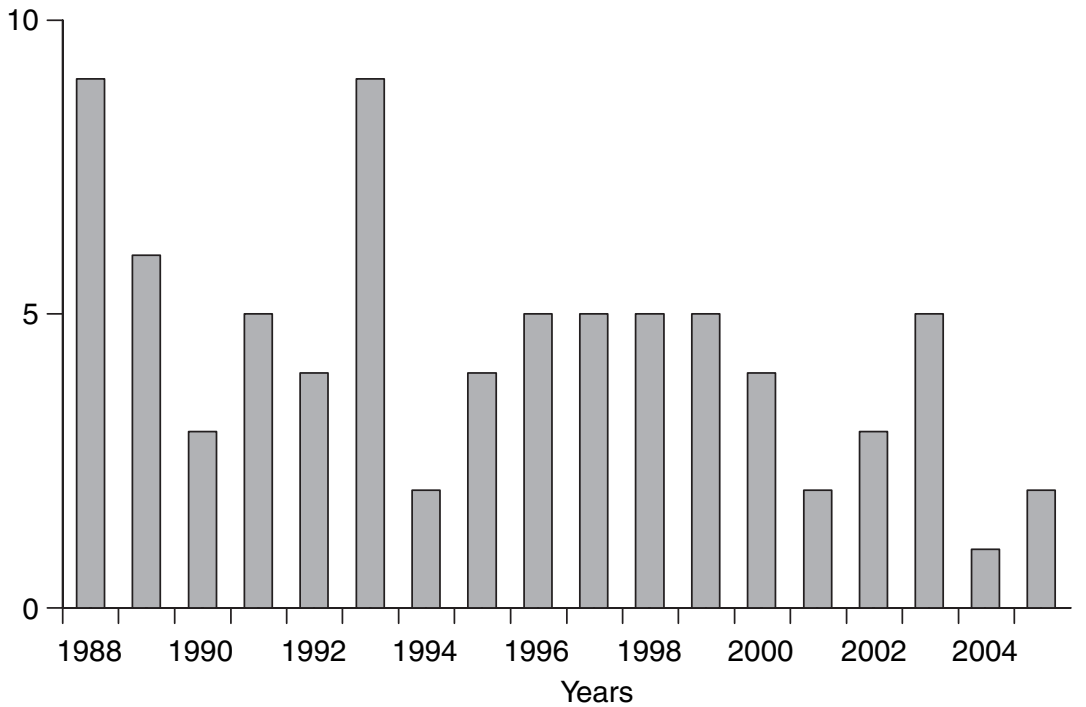

Fig. 18. Theil and Goldberger (1961).

We also include the paper, 'On pure and mixed statistical estimation in economics', by Henri Theil, founding father of the Econometric Institute, and Arthur S. Goldberger which appeared in the International Economic Review, in 1961. This paper has 174 reported citations but only 79 of the 174 belong to the referred period (see Figure 18). 
Table 7. Articles used in citation patterns.

\begin{tabular}{|c|c|}
\hline Article & Citations (reported) \\
\hline KLOEK and van DiJK (1978) & $143(118)$ \\
\hline Rinnooy Kan and Timmer (1987) & $80(80)$ \\
\hline BOYLE and VORST (1992) & $42(41)$ \\
\hline BoswiJk and Franses (1992) & 39 (39) \\
\hline Wagelmans, van Hoesel and Kolen (1992) & $82(79)$ \\
\hline $\begin{array}{l}\text { FleischmanN, Bloemhof-RuwaARD, DeKKer, } \\
\text { VAN DER LAAN, VAN NunEN and VAN WaSSEnhove (1997) }\end{array}$ & $89(89)$ \\
\hline
\end{tabular}

Next, a set of seven papers are selected from the long list of publications as these papers are relatively widely cited and may therefore reveal an interesting duration pattern of citations.

In Table 7 the selected articles (ordered by year of publication) are reported, and the total number of citations (source Web of Science; ISI Thomson Seientific, 2005); between brackets are total number of reported citations [period 1988-2005 (2006)].

The number of citations are displayed in Figs 19-24.

The typical time pattern is one where there exists initially an upward-going movement (see Figure 24) and then a damped fluctuation which tends, after a while, to a 'steady state'. There exist periodic 'precipitation' patterns during which the paper is cited well above its long-run average number. Some papers, in particular the Zellner paper have sufficient energy to maintain a good number of citations and they become an 'evergreen' or 'symphony' that is worth 'hearing' again and again.

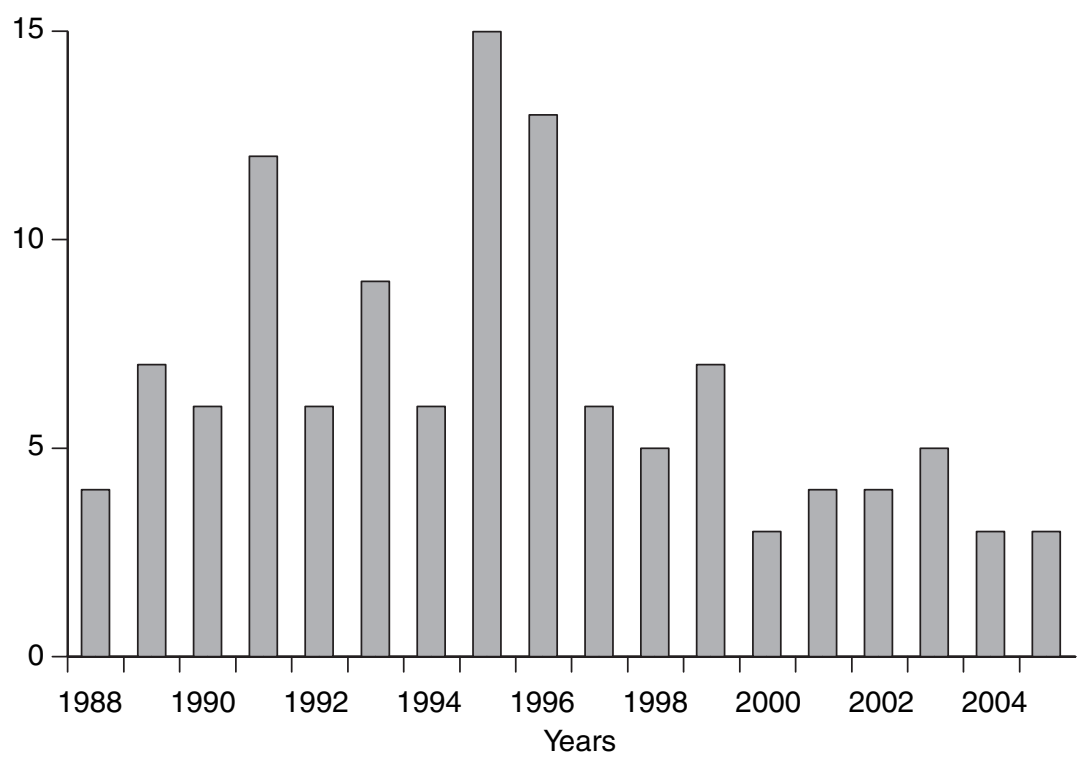

Fig. 19. Kloek and van DiJK (1978). 


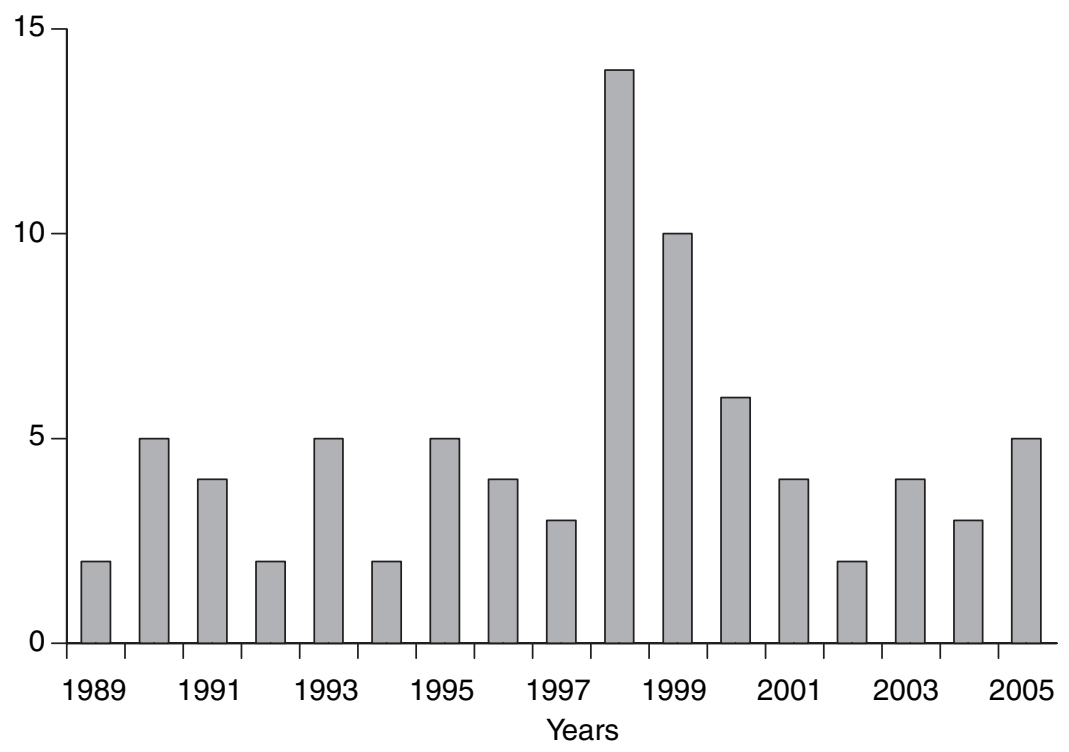

Fig. 20. Rinnooy Kan and Timmer (1987).

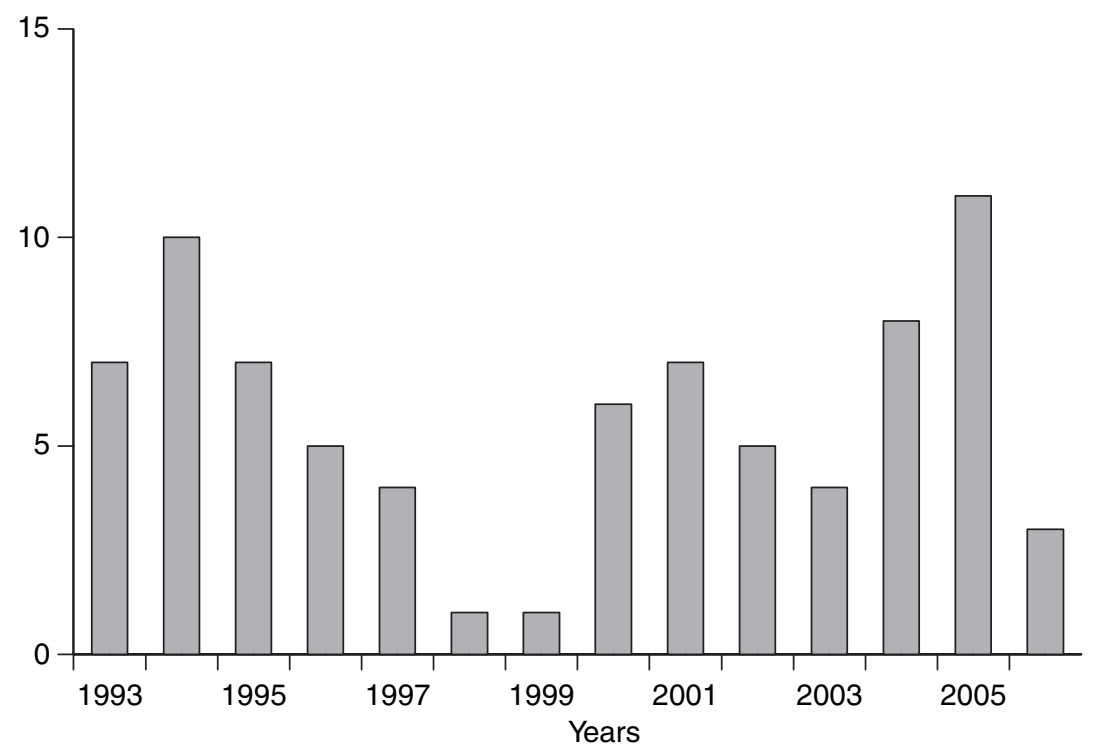

Fig. 21. Wagelmans, van Hoesel and Kolen (1992).

\section{Final remarks}

We have investigated in this paper whether the high reputation of the Econometric Institute, listed in recent rankings of some leading scientific journals, was already in existence in the initial period of the institute and, next, how this reputation moved (c) VVS, 2006 


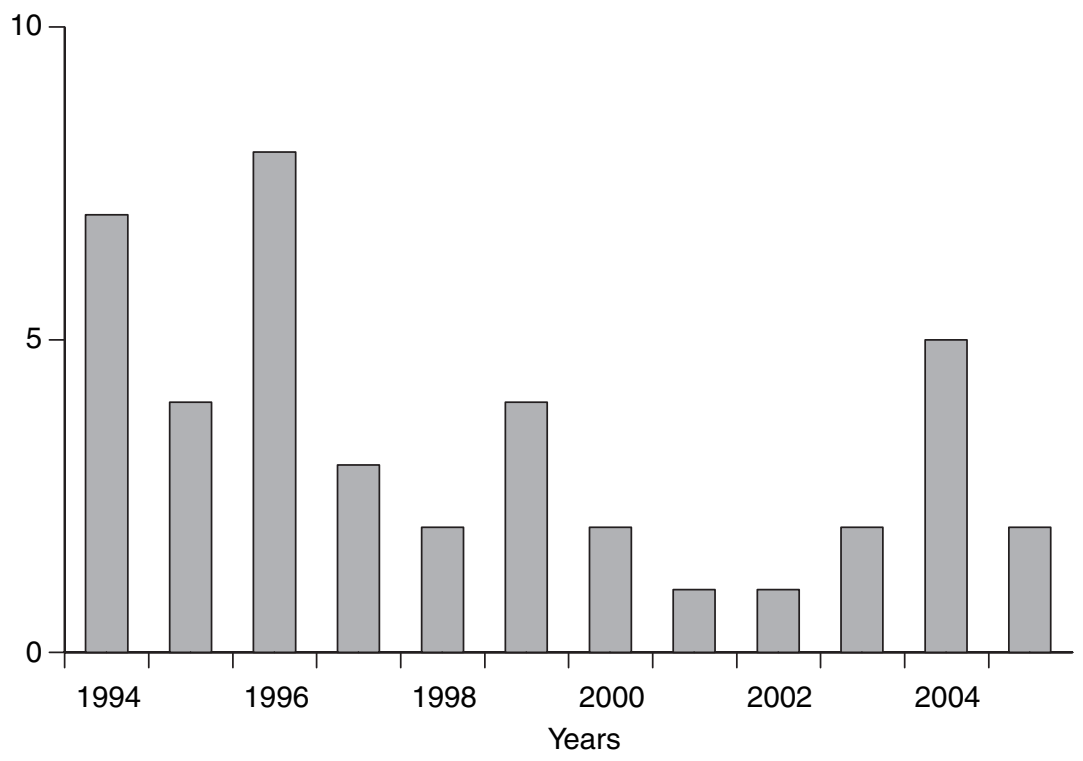

Fig. 22. Boyle and Vorst (1992).

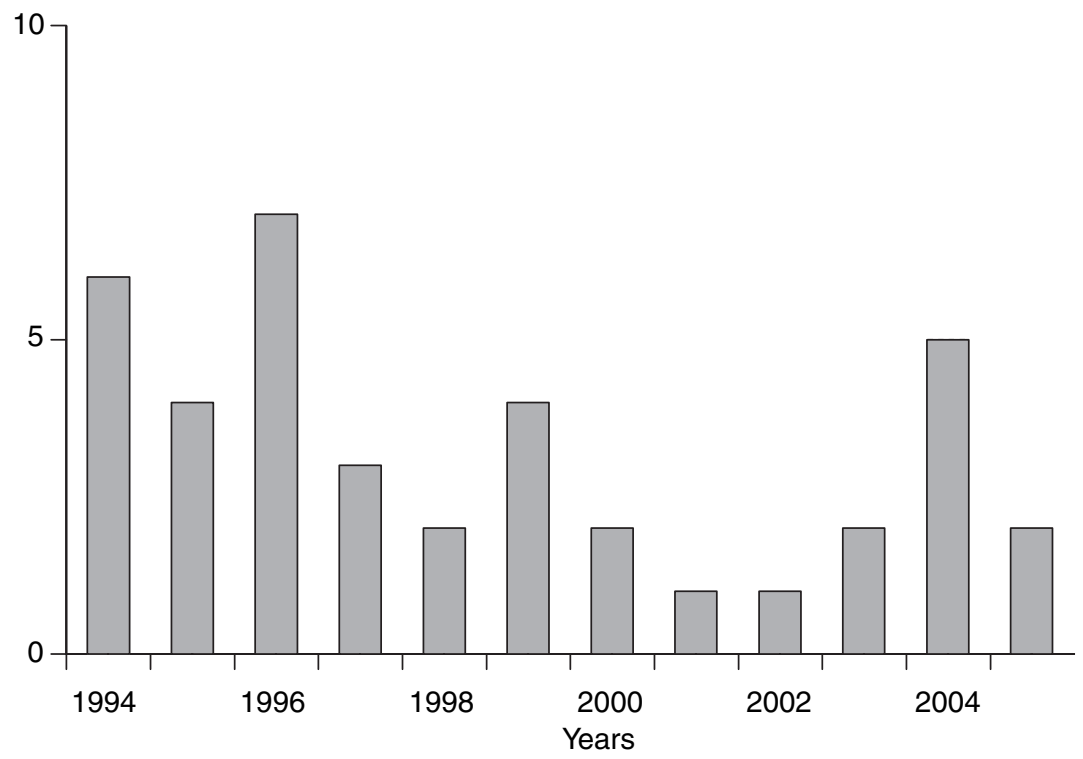

Fig. 23. Boswijk and Franses (1992).

through a 50-year period. Moreover, the distribution of the publications over different research areas is analyzed. In addition, a time-series model is specified to describe and forecast the publication pattern. 


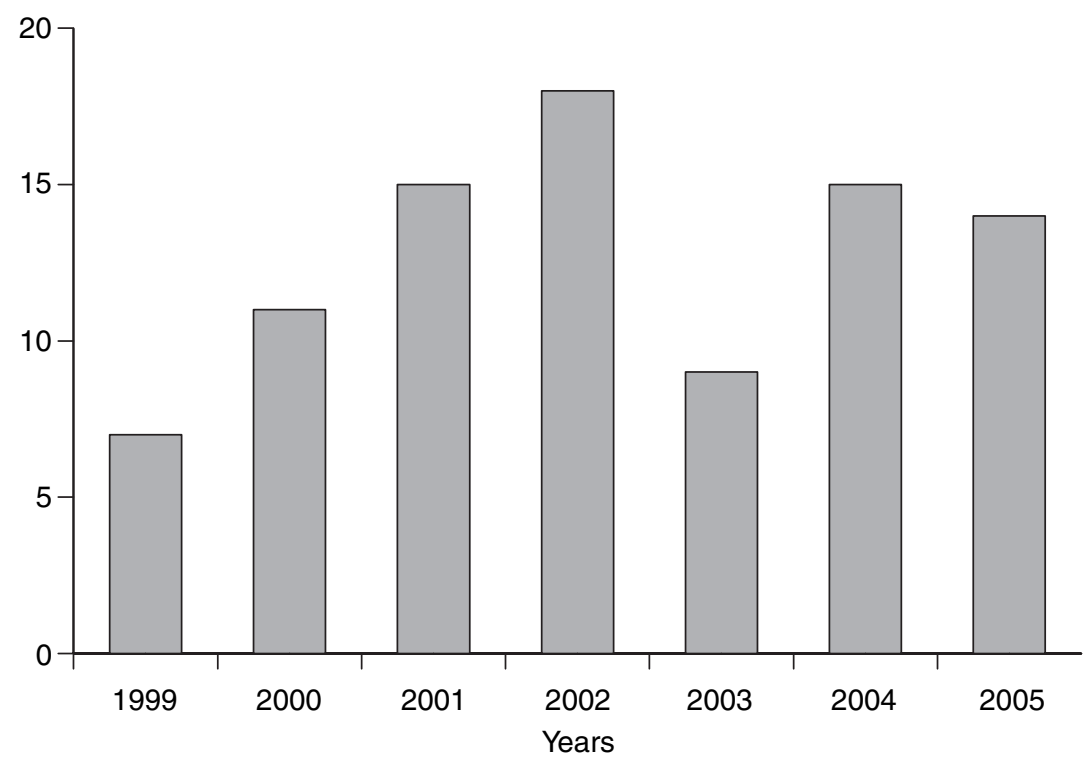

Fig. 24. Fleischmann et al. (1997).

As is usual with the type of exploratory, empirical analysis that has been presented in this paper, one has to be rather careful in drawing strong conclusions. Uncertainty measures of the systematic patterns are missing in several cases. Yet, the following data patterns seem to emerge.

\subsection{Distribution of journal publications}

There is a change in the distribution of journal publications. Members of the Econometric Institute publish, in recent years, less in high-quality journals from learned societies and more in high-quality journals of professional publishers. There is also a change from pure fundamental to a mix of fundamental and solid applied research papers.

\subsection{Fellowships of research schools}

The group around Professor Henri Theil would easily qualify as fellow of the Rotterdam research schools in the 1960s. This is however much more doubtful for the group researchers that were members in the 1970s and early 1980 s.

\subsection{Interdependence, dynamics and nonlinear trend}

There is an upward trend in the number of publications, together with the number of authors, since the late 1970s/early 1980s after an initial very good period in (ㄱ) VVS, 2006 
the 1960s and a rather low number of publications in the early 1970s. Of course, the number of reports affects the number of publications. It takes between 1 and 5 years before a report is published.

\subsection{Long run forecasts}

There are two possible long-run forecasts: it is a challenge for Erasmus University Rotterdam, the Erasmus School of Economics and in particular the staff of the Econometric Institute to reach to the higher level of the forecasts.

\subsection{Citation patterns}

There exist several high-quality papers of Econometric Institute members and their guests that have a rather long-duration pattern in their citations. This is an exception to the more common situation where the life span of citations of scientific papers is only a few years. Aiming for the publication of classic papers remains one of the greatest challenges for any researcher.

\section{Acknowledgements}

The authors are indebted to Mrs Ging Campaña for her assistance in preparing the necessary databases and to the editor of this journal for several useful comments on an earlier version of this paper. Of course, all errors remain the authors' own.

\section{Appendix A: EI publication journals}

In Table A1 the first 40 journals ordered by the number of publication pages by EI members.

Table A1. Econometric Institute publication media ordered by pages.

\begin{tabular}{llr}
\hline Journal & Publications & Pages \\
\hline Statistica Neerlandica & 49 & 698 \\
Econometrica & 33 & 607 \\
Journal of Econometrics & 28 & 589 \\
European Journal of Operational Research & 42 & 530 \\
De Economist & 24 & 459 \\
Mathematical Programming & 16 & 388 \\
Management Science & 24 & 381 \\
Linear Algebra and its Applications & 14 & 306 \\
European Economic Review & 13 & 263 \\
Journal of Optimization Theory and Applications & 13 & 228 \\
Annals of Operations Research & 10 & 218 \\
Nieuw Archief voor Wiskunde & 10 & 214 \\
& & (continued) \\
\hline
\end{tabular}


Table A1. (continued)

\begin{tabular}{|c|c|c|}
\hline Journal & Publications & Pages \\
\hline International Economic Review & 12 & 202 \\
\hline Journal of Applied Econometrics & 10 & 202 \\
\hline Discrete Applied Mathematics & 13 & 195 \\
\hline Annals of Probability & 11 & 187 \\
\hline International Journal of Production Economics & 15 & 174 \\
\hline Journal of the American Statistical Association & 16 & 164 \\
\hline Econometric Reviews & 9 & 158 \\
\hline Mathematics of Operations Research & 10 & 156 \\
\hline International Journal of Forecasting & 13 & 152 \\
\hline Operations Research & 15 & 138 \\
\hline Journal of Empirical Finance & 5 & 136 \\
\hline Journal of Forecasting & 9 & 132 \\
\hline Annals of Discrete Mathematics & 7 & 128 \\
\hline Annals of Statistics & 6 & 126 \\
\hline Journal of Multivariate Analysis & 6 & 121 \\
\hline Journal of the Operational Research Society & 11 & 119 \\
\hline Naval Research Logistics & 7 & 118 \\
\hline Journal of Applied Probability & 8 & 116 \\
\hline Lecture Notes in Mathematics & 6 & 116 \\
\hline Insurance: Mathematics and Economics & 7 & 112 \\
\hline Oxford Bulletin of Economics and Statistics & 7 & 111 \\
\hline Journal of Banking and Finance & 5 & 103 \\
\hline Econometric Theory & 3 & 103 \\
\hline Journal of Global Optimization & 6 & 102 \\
\hline Lecture Notes in Economics and Mathematical Systems & 7 & 97 \\
\hline Economics Letters & 16 & 94 \\
\hline Operations Research Letters & 15 & 93 \\
\hline Empirical Economics & 5 & 92 \\
\hline
\end{tabular}

Table B1. Conversion factors of journals in econometrics(1) and econometrics(2).

\begin{tabular}{llll}
\hline Journal & $\begin{array}{l}\text { Conversion } \\
\text { factor }\end{array}$ & \multicolumn{2}{c}{ Econometrics } \\
\cline { 2 - 4 } American Economic Review & 1.330 & + & + \\
Annals of Statistics & 0.98 & + & \\
Biometrika & 1.15 & + & + \\
Econometrica & 1.000 & + & + \\
Economic Journal & 1.040 & & + \\
Econometric Reviews & N.A. & + & + \\
Econometric Theory & 0.990 & + & + \\
International Economic Review & 1.020 & & + \\
Journal of Applied Econometrics & 1.200 & & + \\
Journal of Business and & & & + \\
Economic Statistics & 1.740 & + & + \\
Journal of Monetary Economics & 0.950 & & + \\
Journal of Political Economy & 0.870 & & + \\
Journal of the & & & + \\
American Statistical Association & 2.020 & & + \\
Journal of the & & + & + \\
Royal Statistical Society & 1.350 & & + \\
Journal of Econometrics & 0.960 & & + \\
Review of Economics and Statistics & 1.430 & & + \\
Review of Economic Studies & 1.220 & & + \\
\hline NA., not analable. & & & + \\
\hline
\end{tabular}

N.A., not available. 
Table C1. Tinbergen Institute

AA journals.

American Economic Review

Econometrica

Journal of Political Economy

Quarterly Journal of Economics

Review of Economic Studies

Table C2. ERIM P* journals.

\begin{tabular}{ll}
\hline Academy of Management Journal & Journal of Marketing \\
Academy of Management Review & Journal of Marketing Research \\
Administrative Science Quarterly & Marketing Science \\
Management Science & Accounting Review \\
Information Systems Research & Journal of Accounting and Economics \\
Mathematics of Operations Research & Journal of Accounting Research \\
MIS Quarterly & Journal of Finance \\
Operations Research & Journal of Financial Economics \\
Journal of Applied Psychology & Journal of Financial and Quantitative Analysis \\
Journal of Management Studies & Review of Financial Studies \\
Organizational Behavior and Human Decision & Journal of International Business Studies \\
$\quad$ Processes & \\
Organization Studies & Journal of Management Studies \\
Research in Organizational Behavior & Organization Science \\
International Journal of Research in Marketing & Organization Studies \\
Journal of Consumer Research & Strategic Management Journal \\
\hline
\end{tabular}

\section{Appendix B: List of journals used by ranking departments}

Table B1 shows lists of econometrics(1), see Table 1 in CRIBARI-Neto et al. (1999), and econometrics(2), see Table 1 in Baltagi (2003).

\section{Appendix C: Tinbergen Institute and ERIM journal rankings}

Only the top ranked journals $\operatorname{TI}(\mathrm{AA})$ and $\operatorname{ERIM}\left(\mathrm{P}^{*}\right)$ are summarized in Tables $\mathrm{C1}$ and $\mathrm{C} 2$; for it the complete list of journals, we refer to the websites, see TI ranking (2005) and ERIM ranking (2005).

\section{Appendix D: All publications EI 1956-2004}

For the complete list of all publications (based on the reprints series of the Econometric Institute) we refer to the website of the Econometric Institute.

\section{Notes}

1. Cribari-Neto et al. (1999) also differentiate between authors still or not any more affiliated with the department. 
2. In a personal comment to the first author in 2003, Jim Heckman mentioned that the socalled Heckman estimator in the discrete choice literature builds upon the earlier work of Theil.

3. For the interested reader, we remark that our numerical results are computed using regression techniques. However, the inferential statement that we have 'confidence' in a result is a Bayesian statement. We adopt a quasi-Bayesian approach in the sense of using regression algorithms for computational purposes and interpreting the strength of estimates in a subjective way.

4. The Johansen cointegration test indicates that the null hypothesis of no cointegration cannot be rejected. As a consequence, we do not pursue this class of models.

5. Source Web of Science (ISI Thomson Scientific, 2005).

\section{References}

Baltagi, B. H. (2003), Worldwide institutional and individual rankings in econometrics over the period 1989-1999: an update, Econometric Theory 19, 165-234.

Bishop, C. M. (1995), Neural networks for pattern recognition, Clarendon Press, Oxford.

Boswisk, P. and Ph. H. B. F. Franses (1992), Dynamic specification and cö̈ntegration, Oxford Bulletin of Economics and Statistics 54, 369-381.

Boyle, Ph. P. and A. C. F. Vorst (1992), Option replication in discrete time with transaction costs, The Journal of Finance 47, 271-293.

Cribari-Neto, F., M. J. Jensen and A. A. Novo (1999), Research in econometric theory: quantitave and qualitative productivity rankings, Econometric Theory 15, 719-752.

van DiJK, H. K. (2004), Twentieth century shocks, trends and cycles in industralized nations, De Economist 152, 211-232.

Fleischmann, M., J. M. Bloemhof-Ruwahrd, R. Dekker, E. van der Laan, J. A. E. E. VAN NUNEN and L. N. van WASSENhove (1997), Quantitative models for reverse logistics: a review, European Journal of Operational Research, 103, 1-17.

ERIM (2005), Ranking list: http://www.erim.eur.nl

Heis, Ch., P. De Boer, Ph. H. Franses, T. Kloek and H. K. van Dijk (2004), Econometric methods and applications in business and economics, Oxford University Press, Oxford.

Hood, W. C. and T. C. Koopmans (eds.) (1953), Studies in econometric method, Yale University Press, New Haven, CT.

ISI Thomson Scientific (2005), Web of Science, http://scientific.thomson.com/products/wos

KaAshoek, J. F. and H. K. van Dijk (2003), Neural networks: an econometric tool, in: D. E. A. Giles (ed.), Computer-aided econometrics, Marcel Dekker, Inc., New York, Basel, 351-384.

KLoeK, T. and H. K. van DiJK (1978), Bayesian estimates of equation system parameters: an application of integration by Monte Carlo, Econometrica 46, 1-19.

Koopmans, T. C. (ed.) (1950), Statistical inference in dynamic economic models, Wiley, New York.

Lubrano, M., L. Bauwens, A. Kirman and C. Protopopescu (2003), Ranking economics departments in Europe: a statistical approach, Journal of the European Economic Association 1, 1367-1401.

Rinnooy Kan, A. H. G. and G. T. Timmer (1987), Stochastic global optimization methods, part I, Mathematical Programming 39, 27-52.

Theil, H. (1953), Repeated least-squares applied to complete equation systems, Central Planning Bureau, The Hague.

THEIL, H. (1953), Estimation and simultaneous correlation in complete equation systems, Central Planning Bureau, The Hague.

Theil, H. and A. S. Goldberger (1961), On pure and mixed statistical estimation in economics, International Economic Review 2, 65-78.

Tinbergen Institute (2005), Ranking list: http://www.tinbergen.nl/research/ranking2.html 
Wagelmans, A. P. M., S. van Hoesel and A. Kolen (1992), Economic lot sizing: an O( $n \log n)$ that runs in linear time in the Wagner-Within case, Operations Research 40 (suppl. 1), 145156.

Zellner, A. (1962), An efficient method of estimating seemingly unrelated regressions and tests for aggregation bias, Journal of the American Statistical Association 57, 348-368.

Received: November 2005. Revised: December 2005. 
Copyright of Statistica Neerlandica is the property of Blackwell Publishing Limited and its content may not be copied or emailed to multiple sites or posted to a listserv without the copyright holder's express written permission. However, users may print, download, or email articles for individual use. 